\title{
Bisphenol A-Induced Epigenetic Changes and Its Effects on the Male Reproductive System
}

\begin{abstract}
Federica Cariati ${ }^{1,2 \star}$, Luigi Carbone ${ }^{3}$, Alessandro Conforti ${ }^{3}$, Francesca Bagnulo ${ }^{2}$, Stefania Ramona Peluso ${ }^{2}$, Consolata Carotenuto ${ }^{4}$, Cira Buonfantino ${ }^{5}$, Erminia Alviggi ${ }^{6}$, Carlo Alviggi ${ }^{2,3,7 \dagger}$ and Ida Strina ${ }^{2,3+}$

${ }^{1}$ CEINGE-Biotecnologie Avanzate s.c.a.r.l., Naples, Italy, ${ }^{2}$ Fertility Unit, Maternal-Child Department, AOU Policlinico Federico II, Naples, Italy, ${ }^{3}$ Department of Neuroscience, Reproductive Sciences and Odontostomatology, Federico II University, Naples, Italy, ${ }^{4}$ Molecular Medicine and Medical Biotechnology Department, Federico II University, Naples, Italy, ${ }^{5}$ Department of Public Health, Federico II University, Naples, Italy, ${ }^{6}$ GENERA Centers for Reproductive Medicine, Clinica Ruesch, Naples, Italy, ${ }^{7}$ Endocrinology and Experimental Oncology Institute (IEOS), National Research Council, Naples, Italy
\end{abstract}

Bisphenol A (BPA) is a widespread chemical agent which can exert detrimental effects on the male reproductive system. Exposure to BPA has been shown to induce several epigenetic modifications in both animal and human cells. Specifically, BPA could not only modify the methylation pattern of multiple genes encoding proteins related to reproductive physiology but also directly influence the genes responsible for DNA methylation. BPA effects include hormonal alterations, microscopic and macroscopic alteration of male reproductive organs, and inheritable epigenetic changes involving human reproduction. BPA exposure was also linked to prostate cancer. This review aims to show the current scenario of BPA-induced epigenetic changes and its effects on the male reproductive system. Possible strategies to counter the toxic effect of BPA were also addressed.

Keywords: bisphenol A, male reproduction, infertility, epigenetic, oxidative stress, DNA methylation, spermatogenesis, prostate cancer

\section{INTRODUCTION}

Epigenetics is the science that studies the environmental influence over the genetic heritage without modifying the DNA sequence. Epigenetic modifications include chromatin remodeling, histone modifications, and non-coding RNA mechanisms, which in turn could affect the phenotype of different types of cells. Epigenetics acts in the regulation of the expression of silencing genes in response to a variety of environmental exposures, allowing cells to answer and adapt to environmental stressors (1). Moreover, epigenetic modifications in parents can determine long-lasting changes, evolving in pathologies for the offspring (1).

It is now acknowledged that widespread chemical agents can exert detrimental effects on human physiology. Some substances identified as "endocrine-disrupting chemicals" (EDC) could also interfere with the endocrine system (2-4).

Bisphenol A (BPA) is an organic synthetic compound largely used for the production of polycarbonate plastics and epoxy resins. Due to the widespread industrial use of polycarbonate plastics (e.g., food/drink packaging, production of compact discs, impact-resistant safety equipment, and medical devices), the presence of BPA is ubiquitous (5). BPA can be detected in various body fluids like urine, saliva, blood, breast milk, and amniotic fluid, as well as on the skin 
(6). The most harmful effect of BPA is due to both its estrogenic and anti-estrogenic properties $(7,8)$. BPA is able to bind to multiple targets both inside and outside the nucleus, inducing alterations in various endocrine-related pathways (7). The effects of BPA on the hypothalamic-pituitary-gonadal axis, determining pathologic consequences on the reproductive system, have been elucidated in animal and human studies (9). In addition to short-term effects, it has been demonstrated that BPA can alter epigenetic mechanisms producing also long-term effects (1).

The ability of BPA to alter normal epigenetic patterns has been recently demonstrated. Some studies revealed a role in the differentiation of spermatogenic cells, through the functional modification of some genes $(10,11)$. This review intends to summarize the epigenetic mechanisms by which BPA acts on both animal and human male reproductive systems. Furthermore, the possible strategies to counteract BPA effects were also disclosed and discussed.

\section{MATERIALS AND METHODS}

The search was conducted using Medline, Embase, Web of Science, Scopus, ClinicalTrials.gov, Ovid, and Cochrane Library as electronic databases. Studies were identified using the combination of the following search terms: "bisphenol A" AND "epigenetic" OR "epigenetic changes" OR "male" OR "male reproduction" OR "reproduction" OR "male reproductive system" OR "sperm” OR "sperm function" OR "sperm changes" OR "spermatogenesis" OR "prostate cancer" OR “oxidative stress" OR "offspring” OR "transgenerational” OR "transgenerational effects" OR "transgenerational changes" OR "DNA methylation," from inception of each database to May 2020. Therefore, all data from both animal and human studies on the relationship among BPA and the different aspects of the male reproductive system were considered for inclusion. However, only data regarding epigenetic changes were included in the review. All discrepancies were resolved by discussion among authors. No restrictions for language were applied. Unpublished studies were not included. Data were presented and categorized in relation to the different level at which BPA may induce impairment of male reproductive system physiology. The list of the genes mentioned throughout the whole text is presented with their proper nomenclature and role in Table $\mathbf{1}$.

\section{Reproductive Endocrine System}

BPA is able to bind hormonal receptors, stimulating, or inhibiting the physiologic pathway. Consequently, the ability to interfere with the hormonal axis has been observed, thereby influencing steroid signaling (12). BPA affects testis competence, varying the gene expression of steroid hormone receptors and influencing the enzymes that catalyze DNA methylation, as demonstrated by in vivo and in vitro animal studies (13-21).

In fishes (adult males of rare minnow Gobiocypris rarus), BPA has been demonstrated to affect the gene expression of steroid hormone biosynthesis, blood-testis barrier, proteolysis, lipid transport, and metabolism (13).

In rats, similar data were obtained, showing how BPA exposure influences the hypothalamic-pituitary-gonadal axis, finally modifying the levels of steroid hormone receptors in testes, with important consequences on sperm parameters as motility and count (14). Again, when neonatal male rats were exposed to BPA for the first 5 days of life, a change in gene expression of estrogen receptors $(\mathrm{ER} \alpha$ and $\mathrm{ER} \beta)$ in adult testis and an increase in both transcript and protein levels of DNA methyltransferases (DNMT3A and DNMT3B) were revealed (15). Interestingly, El Henafy et al. (16) obtained very similar results, analyzing the methylation pattern of DNMT3A and ER $\alpha$, showing hypermethylation for both genes, in male rat pups exposed to BPA by transplacental and trans-lactational routes. In addition, their findings indicated that if the period of exposure was longer (pregnancy plus lactation), the effects were higher, suggesting a dose-response effect (16).

The interference of BPA with hormones is also suggested from an in vivo study in mice, where a flavonoid-based diet was administered to counteract the epigenetic effects induced by BPA. DNA methyltransferase expression was inhibited, with a decrease in epigenetic methylation of ER $\alpha$ and H19/IGF2 genes (the H19 imprinting is associated with IGF2 since they have the same gene locus and common enhancers) and of reproductive hormone levels, thus contrasting BPA's effect (17).

Another mechanism by which epigenetic changes are induced may be the increase in oxidative stress caused by BPA exposure $(18,19)$; in this sense, an in vitro study from Zhang et al. (20) showed that after exposing mouse testicular cells to BPA, the mRNA levels of proteins involved in sexual hormone steroidogenesis as StAR, P450scc, Cyp17a1, and 3 $\beta$-HSD were reduced but were also normalized after exposure to melatonin. Finally, the exposure to BPA in mouse preimplantation embryo produces a disruption of testicular synthesis of testosterone and reduction of StAR promoter histone acetylation, thereby inducing a retard of testis development (21).

\section{Teratogenesis and Gonadal Morphology}

The majority of the studies principally focus on molecular mechanisms of pathophysiological changes and not on proper structural abnormalities. However, some evidence from animal studies showed how the BPA exposure promotes teratogenesis and affects testis morphology.

In zebrafish embryo-larvae, BPA shows teratogenic properties, provoking different anomalies going from cardiac edema to craniofacial abnormalities, spinal malformations, cranial hemorrhage, and yolk sac deformity, depending on dose of exposure (22).

In mice, BPA administration appears to compromise the testis morphology; especially the size of seminiferous tubules and the epithelium were significantly reduced with impairment of spermatogenesis at various stages (21).

Moreover, El Henafy et al. (16) evidenced that BPA could significantly impair anogenital distance, which represents an important measure of genital development, as well as testis and epididymis weight.

Another study showed the involvement of Sertoli cells, essential for physical and nutritional support of developing germ cells, as a target of epigenetic and transcriptome alterations from 
TABLE 1 | Genes studied in relation to BPA exposure and male reproductive system alterations.

\begin{tabular}{|c|c|c|c|}
\hline Acronym & Gene & Role & Reference paragraph \\
\hline DNMT3A & DNA methyltransferase 3 alpha & De novo methylation & $\begin{array}{l}\text { Reproductive endocrine system } \\
\text { Spermatogenesis impairment } \\
\text { Risk of prostatic cancer }\end{array}$ \\
\hline DNMT3B & DNA methyltransferase 3 beta & De novo methylation & $\begin{array}{l}\text { Reproductive endocrine system } \\
\text { Spermatogenesis impairment } \\
\text { Risk of prostatic cancer }\end{array}$ \\
\hline IGF2 & Insulin-like growth factor 2 & $\begin{array}{l}\text { - Imprinted gene only expressed from the paternally inherited } \\
\text { chromosome } \\
\text { - Epigenetic changes at this locus are associated with Wilms tumor, } \\
\text { Beckwith-Wiedemann syndrome, rhabdomyosarcoma, and } \\
\text { Silver-Russell syndrom }\end{array}$ & $\begin{array}{l}\text { Reproductive endocrine system } \\
\text { Spermatogenesis impairment } \\
\text { Transgenerational effects }\end{array}$ \\
\hline StAR & $\begin{array}{l}\text { Steroidogenic acute regulation } \\
\text { protein }\end{array}$ & $\begin{array}{l}\text { Regulation of steroid hormone synthesis by enhancing the conversion } \\
\text { of cholesterol into pregnenolone }\end{array}$ & Reproductive endocrine system \\
\hline P450scc & Cytochrome P450 family & Drug metabolism and synthesis of cholesterol, steroids, and other lipids & Reproductive endocrine system \\
\hline CYP17A1 & Cytochrome P450 family & Drug metabolism and synthesis of cholesterol, steroids, and other lipids & Reproductive endocrine system \\
\hline $3 \beta-\mathrm{HSD}$ & $\begin{array}{l}\text { 3ß-Hydroxysteroid } \\
\text { dehydrogenase }\end{array}$ & $\begin{array}{l}\text { Catalyzation of the oxidative conversion of delta (5)-ene-3-beta-hydroxy } \\
\text { steroids and the oxidative conversion of ketosteroids }\end{array}$ & Reproductive endocrine system \\
\hline EXPO5 & Exportin 5 & $\begin{array}{l}\text { Transport of small RNAs and double-stranded RNA-binding proteins } \\
\text { from the nucleus to the cytoplasm }\end{array}$ & Teratogenesis and gonadal morphology \\
\hline DICER & Ribonuclease type III & Production of small RNA component that represses gene expression & Teratogenesis and gonadal morphology \\
\hline DROSHA & Ribonuclease type III & MicroRNA (miRNA) synthesis & Teratogenesis and gonadal morphology \\
\hline AGO2 & $\begin{array}{l}\text { Argonaute RISC catalytic } \\
\text { component } 2\end{array}$ & Short-interfering-RNA-mediated gene silencing & Teratogenesis and gonadal morphology \\
\hline DNMT1 & DNA methyltransferase 1 & De novo methylation & $\begin{array}{l}\text { Spermatogenesis impairment } \\
\text { Risk of prostatic cancer }\end{array}$ \\
\hline Н3К9Ме3 & Histone H3-lysine 9 & $\begin{array}{l}\text { - Trimethylation at the 9th lysine residue of the histone } \mathrm{H} 3 \text { protein } \\
\text { - Binding heterochromatin protein } 1(\mathrm{HP} 1) \text { to } \\
\text { constitute heterochromatin }\end{array}$ & Spermatogenesis impairment \\
\hline H3K27Me3 & Histone H3-lysine 27 & $\begin{array}{l}\text { - Trimethylation at the } 27 \text { th lysine residue of the histone } \mathrm{H} 3 \text { protein } \\
\text { - Involvement in the peroxisome-associated pathway and induction of } \\
\text { peroxisome loss to ameliorate oxidative stress }\end{array}$ & Spermatogenesis impairment \\
\hline H3K9Me1 & Histone H3-lysine 9 & - Monomethylation at the 9th lysine residue of the histone $\mathrm{H} 3$ protein & Spermatogenesis impairment \\
\hline H3K9Me2 & Histone H3-lysine 27 & $\begin{array}{l}\text { - Dimethylation at the 9th lysine residue of the histone } \mathrm{H} 3 \text { protein } \\
\text { - Mark of the inactivated X chromosome }(\mathrm{Xi})\end{array}$ & Spermatogenesis impairment \\
\hline MYBPH & Histone H3-lysine 9 & Biased expression in prostate & Spermatogenesis impairment \\
\hline PRKCD & Protein kinase $\mathrm{C} \delta$ & Tumor suppressor and cell cycle progression & Spermatogenesis impairment \\
\hline IGF2R & $\begin{array}{l}\text { Insulin-like growth factor } 2 \\
\text { receptor }\end{array}$ & $\begin{array}{l}\text { - Intracellular trafficking of lysosomal enzymes } \\
\text { - Activation of transforming growth factor beta } \\
\text { - Degradation of insulin-like growth factor } 2\end{array}$ & Spermatogenesis impairment \\
\hline G9a & Lysine methyltransferase & Key histone methyltransferase for $\mathrm{H} 3 \mathrm{~K} 9 \mathrm{me} 1$ and $\mathrm{H} 3 \mathrm{~K} 9 \mathrm{me} 2$ & Spermatogenesis impairment \\
\hline GNMT & Glycine N-methyltransferase & $\begin{array}{l}\text { Catalyzation of the conversion of S-adenosyl-L-methionine (along with } \\
\text { glycine) to S-adenosyl-L-homocysteine and sarcosine }\end{array}$ & Spermatogenesis impairment \\
\hline
\end{tabular}


TABLE 1 | Continued

\begin{tabular}{|c|c|c|c|}
\hline Acronym & Gene & Role & Reference paragraph \\
\hline TET & Ten-eleven translocation protein & $\begin{array}{l}\text { Regulation of DNA demethylation, gene transcription, embryonic } \\
\text { development, and oncogenesis }\end{array}$ & Spermatogenesis impairment \\
\hline LINE-1 & $\begin{array}{l}\text { Long interspersed nucleotide } \\
\text { elements } 1\end{array}$ & $\begin{array}{l}\text { - Gene regulation by the } 5^{\prime} \text { UTR methylation level } \\
\text { - Active in germ cells and silent in most of the somatic cells }\end{array}$ & Spermatogenesis impairment \\
\hline $\mathrm{ACHE}$ & Acetylcholinesterase & $\begin{array}{l}\text { Hydrolyzation of the neurotransmitter acetylcholine in choline and } \\
\text { acetic acid }\end{array}$ & Spermatogenesis impairment \\
\hline H3K27 & Histone H3-lysine 27 & $\begin{array}{l}\text { - Epigenetic mark } \\
\text { - Regulation of chromatin structure and gene expression }\end{array}$ & Transgenerational effects \\
\hline $\mathrm{H} 4 \mathrm{~K} 12$ & Histone H4-lysine 12 & $\begin{array}{l}\text { - Epigenetic mark } \\
\text { - Regulation of chromatin structure and gene expression }\end{array}$ & Transgenerational effects \\
\hline SIRT1 & Sirtuin 1 & $\begin{array}{l}\text { Regulation of epigenetic gene silencing and suppression of rDNA } \\
\text { recombination }\end{array}$ & Transgenerational effects \\
\hline $\mathrm{ER} \beta$ & Estrogen receptor $\beta$ & $\begin{array}{l}\text { - Transcription activation } \\
\text { - Inhibition of the activity of other estrogen receptor family members }\end{array}$ & Transgenerational effects \\
\hline CAV-1 & Caveolin 1 & $\begin{array}{l}\text { Involvement in the Ras-ERK pathway and promotion of cell cycle } \\
\text { progression }\end{array}$ & Transgenerational effects \\
\hline IGF2R & $\begin{array}{l}\text { Insulin-like growth factor } 2 \\
\text { receptor }\end{array}$ & $\begin{array}{l}\text { - Intracellular trafficking of lysosomal enzymes } \\
\text { - Activation of transforming growth factor beta } \\
\text { - Degradation of insulin-like growth factor } 2\end{array}$ & Transgenerational effects \\
\hline PEG3 & Paternally expressed 3 gene & $\begin{array}{l}\text { - Paternally expressed } \\
\text { - Involvement in cell proliferation and p53-mediated apoptosis }\end{array}$ & Transgenerational effects \\
\hline SLC12A2 & $\mathrm{Na}-\mathrm{K}-\mathrm{Cl}$ cotransporter & Mediation of sodium and chloride transport and reabsorption & Risk of prostatic cancer \\
\hline PDE4D4 & Phosphodiesterase 4D4 & 3',5'-Cyclic-AMP phosphodiesterase activity and cAMP degradation & Risk of prostatic cancer \\
\hline HPCAL1 & Hippocalcin-like 1 & $\begin{array}{l}\text { Calcium-dependent regulation of rhodopsin phosphorylation with } \\
\text { implication in neuronal signaling in the central nervous system }\end{array}$ & Risk of prostatic cancer \\
\hline MBD2 & $\begin{array}{l}\text { Methyl-CpG-binding domain } \\
\text { protein } 2\end{array}$ & $\begin{array}{l}\text { - Binding specifically to methylated DNA sequences } \\
\text { - Transcription repression from methylated gene promoters } \\
\text { - Mediation of the biological consequences of the methylation signal }\end{array}$ & Risk of prostatic cancer \\
\hline GPCR14 & $\begin{array}{l}\text { Putative G-protein coupled } \\
\text { receptor }\end{array}$ & $\begin{array}{l}\text { Mediation of signaling processes to the interior of the cell via activation } \\
\text { of heterotrimeric } G \text { proteins }\end{array}$ & Risk of prostatic cancer \\
\hline PDGFR $\alpha$ & $\begin{array}{l}\text { Platelet-derived growth factor } \\
\text { receptor alpha }\end{array}$ & Mitogenesis for cells of mesenchymal origin & Risk of prostatic cancer \\
\hline PLCß33 & Phospholipase C beta 3 & $\begin{array}{l}\text { Catalyzation of the diacylglycerol and inositol 1,4,5-triphosphate from } \\
\text { phosphatidylinositol in G-protein-linked receptor-mediated signal } \\
\text { transduction }\end{array}$ & Risk of prostatic cancer \\
\hline NSBP1 & Nucleosomal binding protein 1 & Nucleosomal binding and transcriptional activating protein & Risk of prostatic cancer \\
\hline HMGN5 & $\begin{array}{l}\text { High-mobility group } \\
\text { nucleosome-binding domain } 5\end{array}$ & Nucleosomal binding and transcriptional activating protein & Risk of prostatic cancer \\
\hline PITX3 & Paired-like homeodomain 3 & Lens formation during eye development & Risk of prostatic cancer \\
\hline WNT10B & Wnt family member $10 \mathrm{~B}$ & $\begin{array}{l}\text { - Oncogenesis } \\
\text { - Regulation of cell fate and patterning during embryogenesis }\end{array}$ & Risk of prostatic cancer \\
\hline PAQR4 & $\begin{array}{l}\text { Progestin and adipoQ receptor } \\
\text { family member } 4\end{array}$ & Tumor suppression by inhibition of the Raf/MEK/ERK signaling cascade & Risk of prostatic cancer \\
\hline SOX2 & SRY-box transcription factor 2 & Regulation of embryonic development and determination of cell viability & Risk of prostatic cancer \\
\hline CHST14 & $\begin{array}{l}\text { Carbohydrate sulfotransferase } \\
14\end{array}$ & $\begin{array}{l}\text { Catalyzation of sulfate transfer to the C-4 hydroxyl of } \\
\mathrm{N} \text {-acetylgalactosamine residues in dermatan sulfate }\end{array}$ & Risk of prostatic cancer \\
\hline TPD52 & Tumor protein D52 & Tumor progression & Risk of prostatic cancer \\
\hline CREB3L4 & $\begin{array}{l}\text { CAMP-responsive } \\
\text { element-binding protein } 3 \text { like } 4\end{array}$ & Adiposity and male germ cell development & Risk of prostatic cancer \\
\hline $\mathrm{EZH} 2$ & $\begin{array}{l}\text { Enhancer of zeste } 2 \text { polycomb } \\
\text { repressive complex } 2 \text { subunit }\end{array}$ & $\begin{array}{l}\text { Maintaining of the transcriptional repressive state of genes over } \\
\text { following cellular generations }\end{array}$ & Risk of prostatic cancer \\
\hline UHRF1 & $\begin{array}{l}\text { Ubiquitin-like with PHD and ring } \\
\text { finger domains } 1\end{array}$ & Regulation of gene expression & Risk of prostatic cancer \\
\hline BCR & Breakpoint cancer region & $\begin{array}{l}\text { - Serine/threonine kinase activity } \\
\text { - GTPase activation of protein for p21rac and other kinases }\end{array}$ & \\
\hline
\end{tabular}


TABLE 1 | Continued

\begin{tabular}{|c|c|c|c|}
\hline Acronym & Gene & Role & Reference paragraph \\
\hline PTGS2 & $\begin{array}{l}\text { Prostaglandin-endoperoxide } \\
\text { synthase } 2\end{array}$ & Involvement in prostaglandin biosynthesis & Risk of prostatic cancer \\
\hline TIMP3 & $\begin{array}{l}\text { Tissue inhibitor of } \\
\text { metalloproteinase } 3\end{array}$ & $\begin{array}{l}\text { Inhibition of the matrix metalloproteinases with a role in tumor } \\
\text { suppression }\end{array}$ & Risk of prostatic cancer \\
\hline ZMYDN10 & $\begin{array}{l}\text { Loss of zinc finger MYND-type } \\
\text { containing } 10\end{array}$ & Tumor suppressor & Risk of prostatic cancer \\
\hline GSTP1 & Glutathione S-transferase Pi 1 & $\begin{array}{l}\text { Detoxification by catalyzing the conjugation of many hydrophobic and } \\
\text { electrophilic compounds with reduced glutathione }\end{array}$ & Risk of prostatic cancer \\
\hline LOX & Lysyl oxidase & Tumor suppression & Risk of prostatic cancer \\
\hline MGMT & $\begin{array}{l}\text { O-6-Methylguanine-DNA } \\
\text { methyltransferase }\end{array}$ & Cellular defense against mutagenesis and toxicity from alkylating agents & Risk of prostatic cancer \\
\hline NEUROG & Neurogenin 1 & Transcriptional regulator & Risk of prostatic cancer \\
\hline TSC2 & TSC complex subunit 2 & Tumor suppression & Risk of prostatic cancer \\
\hline PDLIM4 & PDZ and LIM domain 4 & Bone development & Risk of prostatic cancer \\
\hline PYCARD & $\begin{array}{l}\text { PYD and CARD domain } \\
\text { containing }\end{array}$ & $\begin{array}{l}\text { Mediation of signaling complex assembly in the inflammatory and } \\
\text { apoptotic signaling pathways via the activation of caspase }\end{array}$ & Risk of prostatic cancer \\
\hline KDM5B & Lysine demethylase 5B & Transcriptional repression & Risk of prostatic cancer \\
\hline NSD1 & $\begin{array}{l}\text { Nuclear receptor-binding SET } \\
\text { domain protein } 1\end{array}$ & Androgen receptor transactivation & Risk of prostatic cancer \\
\hline
\end{tabular}

environmental toxicant exposures. These epigenetic alterations are related to testis abnormalities (23).

Cho et al. studied the influence of BPA on micro-RNA (miRNA): in mouse Sertoli cell lines, the BPA was shown to alter miRNA expression, with subsequent gene expression modification, and related changes in reproductive patterns (24).

An in vitro study on testicular fragments culture from 7-dayold male pigs exposed to BPA demonstrated a downregulation of EXPO5 and Dicer genes and an upregulation of Drosha and AGO2 genes, involved in miRNA pathways. Also, Leydig cells' morphology was not altered but interstitial tissue collagen was increased (25).

\section{Spermatogenesis Impairment}

Epigenetic modifications can occur at different steps during spermatogenesis. Firstly, primordial germ cells are subjected to genomic imprinting through a process of DNA/histone demethylation and deacetylation of $\mathrm{H} 4$ (Histone 4). DNA methyltransferases already expressed at this stage are DNMT3A, DNMT3B, and DNMT3L. Then, de novo DNA methylation occurs in spermatogonia and remains stable until fertilization and zygote development (26). This mechanism appears necessary to complete spermatic meiosis, as suggested in a study in which DNA methyltransferase knockout mice resulted to be sterile because they were unable to sustain meiosis (26). Furthermore, $\mathrm{H} 3 \mathrm{~K} 9$ and $\mathrm{H} 3 \mathrm{~K} 4$ methylation takes place in spermatocytes; DNMT1 is expressed in round spermatids, where hyperacetylated $\mathrm{H} 4$ is found and replacement of histone variants by transition proteins is starting. Elongated spermatids show establishment of a DNA methylation pattern associated with histone $\mathrm{H} 3 \mathrm{~K} 9$ demethylation. The histone-to-protamine transition is completed at this stage of spermatogenesis. Finally, the genomic imprinting is saved in spermatozoa
(27). The histone-to-protamine transition permits a packaging of spermatic DNA, with condensation of sperm heads and protection of DNA from damage and mutagenesis. However, a low percentage of histones can remain in sperm, at undefined genes or gene promoter levels, causing possible post-translational modifications, resulting in severely altered reproductive phenotypes $(11,28,29)$. It has been demonstrated that the alteration of the histone-protamine ratio affects male fertility (27).

In mice, in vitro studies on testis germ cells exposed to high doses of BPA demonstrated a decrease in the global DNA methylation levels, due to a reduction in DNMT1 protein and mRNA. At the same time, histone hypomethylation of H3K9Me3, H3K27Me, H3K9Me1, and H3K9Me2 was revealed. These changes seem to be mediated by a reduction in G9a proteins, which are essential methyltransferases for the meiotic process and hence for the whole spermatogenesis $(20,30)$.

The toxic effect of BPA on mouse semen quality was demonstrated from Zhang et al., who observed an increased number of morphologically altered and headless spermatozoa; in addition, sperm motility was reduced, after subcutaneous injection or feeding with BPA (31). Yin et al. demonstrated the alteration of DNA methylation of MYBPH and PRKCD, eliciting a change in spermatocyte proliferation and motility in a murine model (32).

In fishes, several studies showed that BPA exposure causes an impairment of global DNA methylation in the testes and consequently reduced rate of fertilization (33-36).

In details, in Gobiocypris rarus, BPA-induced DNA hypermethylation was demonstrated and explained by several mechanisms, including de novo synthesis of glutathione and oxidative stress, in addition to a significant decrease of the TET protein levels, responsible for demethylation $(33,36,37)$. 
It was also observed that administration of antioxidants as $\mathrm{N}$-acetylcysteine may reverse such damages, protecting DNA integrity and sperm motility (36).

On the contrary, in zebrafish gonads, a global DNA demethylation due to a transcriptional miss-regulation of the DNA methylation/demethylation-associated genes (DNMTs, GNMT, and TETs) was noticed $(35,38)$. Moreover, a compromised spermatogenesis in male zebrafish exposed to a high dose of BPA was demonstrated. As a matter of fact, a significant decrease in sperm count was seen together with an increase in apoptosis; in addition, a miss-regulation of transcription of enzymes responsible for epigenetic remodeling was proven, leading to an increase in histone acetyltransferase activity and causing alterations in embryo development $(34,39)$.

In Danio rerio zebrafish, Lombó et al. observed sperm DNA fragmentation dependent on dose and time of BPA exposure (6).

In humans, the dimethylation of histone $\mathrm{H} 3$ on lysine $\mathrm{K} 4$ has been demonstrated to be negatively correlated with sperm concentration, motility, and mitochondrial function (40). In particular, a genome-wide study on semen samples from workers exposed to BPA and unexposed controls showed the ability of that compound to interfere with gene expression during spermatogenesis, with DNA hydroxymethylation due to $\mathrm{H} 3$ trimethylation, clinically ending in reduced sperm concentration motility (41). More recent data confirm previous findings, especially demonstrating a LINE-1 hydroxymethylation (42). Since LINE-1 activation has already been studied in relation to male infertility, its epigenetic modifications induced by BPA exposure may be one of the mechanisms for this EDC's toxicity. In another study, blood and semen samples collected from BPA exposed vs. non-exposed men were analyzed, in order to evaluate the toxic effect on a marker of genome-wide methylation status as LINE-1. Results showed a significantly lower methylation level of sperm LINE-1 in workers exposed to BPA. In addition, the BPA urinary levels were associated with low semen quality, even though they were inversely correlated with LINE-1 methylation (43).

Men exposed to BPA showed an increase in the rate of 5-hydroxymethylcytosine (5-hmc, which is a marker of DNA demethylation processes and demonstrates active gene transcription) of the sperm ACHE gene. Therefore, the accumulation of $5-\mathrm{hmc}$ is associated with demethylation status. Taking into consideration that this type of alteration is correlated with sperm concentration and motility, the authors suggested that male infertility could be a consequence of BPA exposure $(10,44)$. Indeed, the effects of BPA on spermatogenesis are widely discussed in literature, whereas the majority of the studies do not explicitly mention if the underlying pathogenetic mechanisms are epigenetic $(5,14)$.

Moreover, since the effects of BPA exposure are also unfolded by DNA damage and epigenetic modifications, information on the influence of BPA on spermatogenesis and related male infertility is derived not only by studies directly analyzing sperm parameters but also through evidence of embryo and offspring abnormalities, as for transgenerational effects, thus described accordingly.

\section{Transgenerational Effects}

The process of DNA methylation is closely linked to the well-known phenomenon of genomic imprinting, wherein a gene is differentially expressed depending on whether it has been inherited from the mother or from the father. Examples of imprinting-derived diseases are Angelman syndrome and Prader-Willi syndrome. These, although caused by the epigenetic modification of the same gene, elicit different consequences depending on which parent it has been inherited from (45).

When a "safe" dose of bisphenol A was administered for a long time in rats, a decrease in histone acetylation of $\mathrm{H} 3 \mathrm{~K}$, $\mathrm{H} 3 \mathrm{~K} 27$, and H4K12, an increase in deacetylase Sirt1 expression with reduced binding, and finally an increase in estrogen receptor $\beta$ (ER $\beta$ ) to caveolin-1 (Cav-1) binding were observed. These processes and the related findings provided clues about the underlying mechanisms for epigenetic inheritance induced by BPA exposure (46).

An indirect proof of alteration of the sperm epigenome came from the study of Doshi et al., who evaluated the percentage of post-implantation loss and expression of DNMTs in embryos of pregnant female rats coupled with BPA-exposed males. They pointed out that post-implantation loss rate appeared to be higher and resorbed embryos had lower expression of DNMTs when sired by BPA-exposed males, compared to viable embryos from both BPA-exposed and control males (47). In addition, in their following work on the imprinting control region (ICR) of two genes implicated in embryonic growth and cellular proliferation, H19 and IGF2, the methylation pattern was analyzed. The authors showed hypomethylation at the H19-ICR in both spermatozoa and resorbed embryos from neonatally BPAexposed rats, demonstrating that epigenetic mechanisms regulate both infertility, and transmission to offspring (48).

Oppositely, Zhang et al. noticed no changes in methylation of IGF2, IGF2R, Peg3, and H19, which are imprinted genes. However, they acknowledged that the offspring of BPA-exposed mice had smaller size and worse pelage quality, thus admitting a certain effect of this compound (31).

Shi et al. demonstrated how BPA modifies the mRNA expression of DNA and histone methyltransferases and their associated factors in the testis of a generation of mouse neonates prenatally exposed to that compound and how these effects were transmitted to the third generation of offspring (49).

In Danio rerio zebrafish, treatment with BPA during embryogenesis did not impact the methylation profile of sperm, although a decrease in $\mathrm{H} 3 \mathrm{~K} 9 \mathrm{ac}$, involved in sperm development, was observed (50).

An in vivo study on adult zebrafish males exposed to BPA during spermatogenesis and mated with non-exposed females revealed a disruption of cardiogenesis in forthcoming generations (51).

Akhter et al. studied the appearance of different malformations in various generations of zebrafish, after that the parental generation was exposed to BPA, finding abnormalities in the testes of the second-generation males and explaining this as a trans-generational effect most probably due to epigenetic mechanisms (52). 
Other lines of evidence from animal studies showed that sperm motility was associated with methylation variation affecting genes involved in chromatin organization. The result of this alteration could affect embryo development $(53,54)$.

In a study on perinatal exposure of pregnant rats to BPA, the authors observed male fertility impairments in the three subsequent generations (13).

Hong et al. observed a reduction in the population of all sperm cells at different stages of development (spermatogonia, spermatocytes, and spermatids) in adult mouse testes, after exposure of preimplantation embryos to low-dose BPA, suggesting it as a consequence of epigenetic mechanisms (21).

Moreover, male rats subjected to neonatal BPA exposure showed downregulation of DNMT gene expression and related transcription factors, with impact on sperm epigenome and therefore influence on embryo development and implantation process (47).

In addition, after fetal exposure to BPA in utero, male rats were mated with unexposed female rats: the results showed an epigenetic alteration of IGF2 methylation in the male germline and subsequently promotion of glucose intolerance and $\beta$-cell dysfunction in the offspring, proving therefore the inheritance of epigenetic pattern changes, leading to dysregulation and disease $(55,56)$.

Furthermore, a study on pregnant rats exposed to environmental compounds including BPA during embryonic gonadal sex determination showed pubertal abnormalities, testis disease, obesity, and ovarian disease in the third generation. Apoptosis of spermatogenic cells resulted to be impaired through different generations of offspring (57). Moreover, 197 differential DNA methylation regions (DMR) in the gene promoter were shown in the sperm epigenome in the third generation after exposure. Authors stated that the sperm DMRs could represent epigenetic biomarkers for transgenerational disease and/or ancestral environmental exposures (58).

\section{Risk of Prostatic Cancer}

Ho et al. identified 28 genes as possible markers of epigenetic modifications, looking in particular to DNA methylation, leading to increased predisposition to adult-onset prostate cancer in rats, after neonatal estrogenic or BPA exposure. The majority of such genes were implicated in signal transduction pathways: $\mathrm{Na}-\mathrm{K}-\mathrm{Cl}$ cotransporter (SLC12A2), mitogen-activated protein kinase (MAPK)/extracellular signal-regulated kinase (ERK) pathway (GPCR14 and PDGFR $\alpha$ ), phosphokinase C pathway (PLCB3), and cAMP pathways (PDE4D4 and HPCAL1). In particular, the prostatic PDE4D4 gene remains expressed in all rats early exposed to a low dose of BPA, before adult-onset prostatic lesions; in addition, HPCAL1 showed a specific methylation and expression alteration with aging. Therefore, the authors concluded that early exposure to BPA could provoke permanent impairment of the prostate epigenome, determining a predisposition to prostate cancer (59-62). Later, Tang et al. showed that few genes, such as DNMT3A, DNMT3B, and MBD2,

TABLE 2 | Characteristics of the studies which analyzed hormonal axis disturbances.

\begin{tabular}{|c|c|c|c|c|}
\hline Epigenetic modifications & Effects & Study type & Species & References \\
\hline Genes expression & $\begin{array}{l}\text { - Induction of gene expression in the renin-angiotensin system pathway } \\
\text { - Inhibition of tRNA processing-related gene expression } \\
\text { - Decreases in hemostasis and blood coagulation-related gene expression }\end{array}$ & In vivo & Fish & $(13)$ \\
\hline DNA methylation & $\begin{array}{l}\text { - Hypermethylation of ER } \alpha / E R \beta \text { promoter regions } \\
\text { - Increase in DNMT3A and DNMT3B expression }\end{array}$ & In vivo & Rat & $(15)$ \\
\hline DNA methylation & Hypermethylation within DNMT3A and ER $\infty$ & In vivo & Rat & $(16)$ \\
\hline DNA methylation & $\begin{array}{l}\text { - Hypermethylation of the } \mathrm{ER} \alpha \text { promoter and H19/lgf2 imprinting control } \\
\text { region in the testis } \\
\text { - Increase of DNMT expression }\end{array}$ & In vivo & Mouse & $(17)$ \\
\hline DNA methylation & $\begin{array}{l}\text { - Decrease in G9a-dependent H3K9 di-methylation } \\
\text { - Impairment of spermatogenesis }\end{array}$ & In vitro & Mouse & $(20)$ \\
\hline Histone acetylation & $\begin{array}{l}\text { - Decrease in H3 and H3K14 acetylation in the StAR and P450 in the testes } \\
\text { - Decrease in the expressions of testicular StAR and P450scc }\end{array}$ & In vivo & Mouse & $(21)$ \\
\hline
\end{tabular}

TABLE 3 | Characteristics of the studies which analyzed morphological alterations.

\begin{tabular}{|c|c|c|c|c|}
\hline Epigenetic modifications & Effects & Study type & Species & References \\
\hline Histone acetylation & $\begin{array}{l}\text { Reduction in diameter and epithelium height of seminiferous tubules and } \\
\text { spermatogenic cells at different stages }\end{array}$ & In vivo & Mouse & $(21)$ \\
\hline Gene expression & $\begin{array}{l}\text { Upregulation or downregulation of } 37 \text { miRNA related to overexpression of } \\
\text { genes implicated in metabolism and reproduction }\end{array}$ & In vitro & Mouse & (24) \\
\hline miRNA biogenesis and function & $\begin{array}{l}\text { - No changes in Leydig cell morphology } \\
\text { - No changes in lipid droplet content and distribution } \\
\text { - Changes in lipid and autophagy protein abundance } \\
\text { - Downregulation of EXPO5 and Dicer genes and an upregulation of } \\
\text { Drosha and AGO2 genes }\end{array}$ & In vitro & Boar & (25) \\
\hline
\end{tabular}


responsible for epigenetic mechanisms, were overexpressed in rats after early exposure to BPA. Moreover, this study defined three patterns of epigenetic changes, characterizing genes like NSBP1 and HMGN5, persistently present epigenetic markers of early-life exposure; a second group represented by PDE4D4, which appear only at genital maturation but persist throughout life; and the last group, including genes such as HPCAL1 considered modifiable epigenetic markers, whose later appearance depends on early-exposure features and subsequent events during adult life (63). Moreover, Cheong et al. analyzed the prostatic tissue of BPA early-exposed rats for the methylation pattern of 7 genes (PITX3, WNT10B, PAQR4, SOX2, CHST14, TPD52, and CREB3L4), at the promoter region, showing that 4 of them (PITX3, WNT10B, PAQR4, and TPD52) were differently methylated when comparing prostatic cancer cells with normal adjacent tissues. They also noticed a connection with recurrencefree survival of prostatic cancer patients (64). Interestingly, Prins et al., discovered that different prostatic regions and lobes in rats have variable sensitivities to different doses of early-administered
BPA in later-developing cancerous lesions, with different dose-dependent methylation patterns: CREB3L4, TPD52, and PITX3 showed a noteworthy hypomethylation at lower doses of BPA, with a normalization toward higher doses; PAQR4 showed significant hypomethylation for all BPA doses; and SOX2 showed an inverse correlation between hypomethylation and BPA doses (65). In a study on healthy primary human prostate epithelial cells (PrECs) exposed to high concentrations of BPA and analyzed using a whole-genome microarray, the authors noticed that BPA can modify the expression of epigenetic factors as EZH2, DNMT1, DNMT3B, and UHRF1, producing transcriptional perturbations with epigenetic consequences and even raising cancer risks (66). In addition, Karaman et al., studying prostatic carcinoma cells, observed hypermethylation in the p16 promoter region as well as for BCR, PTGS2, TIMP3, and ZMYDN10, with different changes seen in GSTP1, LOX, MGMT, NEUROG, and TSC2 methylation pattern. Also, a low dose of BPA could determine hypomethylation of PDLIM4 and PYCARD. Moreover, exposure to BPA induces downregulation

TABLE 4 | Characteristics of the studies which analyzed the epigenetic impairment of spermatogenesis.

\begin{tabular}{|c|c|c|c|c|}
\hline Epigenetic modifications & Effects & Study type & Species & References \\
\hline Histone methylation & $\begin{array}{l}\text { - Decrease of DNMT } \\
\text { - Reduction in the global DNA methylation levels in spermatogonia }\end{array}$ & In vitro & Mouse & (30) \\
\hline DNA methylation & $\begin{array}{l}\text { - No effect on DNA methylation of imprinted genes (IGF2, IGF2R, PEG3. and H19) in } \\
\text { - Increase in ER } \alpha \text { expression } \\
\text { - Impairment of meiotic progression of germ cells } \\
\text { - Decrease in quality and quantity of spermatozoa }\end{array}$ & In vivo & Mice & (31) \\
\hline DNA methylation & $\begin{array}{l}\text { - Reduction in DNA replication capacity } \\
\text { - Alteration of the genome-wide DNA methylation level in GC-2 cells } \\
\text { - Alteration of DNMT expression levels } \\
\text { - Regulation of MYBPH and PRKCD methylation }\end{array}$ & In vivo & Mouse & $(32)$ \\
\hline DNA methylation & $\begin{array}{l}\text { Promotion of the DNA methylation process in the testes by novo synthesis of } \\
\text { glutathione and oxidative stress }\end{array}$ & In vivo & Fish & (33) \\
\hline DNA methylation & Alteration of the global DNA methylation level of gonads & In vivo & Fish & (34) \\
\hline DNA methylation & $\begin{array}{l}\text { - Alteration of the global DNA methylation level of gonads } \\
\text { - Transcriptional change of genes (DNMTS, GNMT, and TEST) }\end{array}$ & In vivo & Fish & (35) \\
\hline DNA methylation & Variation in DNA methylation levels & In vivo & Fish & $(36)$ \\
\hline DNA methylation & Hypermethylation of global DNA in the testes & In vivo & Fish & $(37)$ \\
\hline DNA methylation & Global DNA demethylation & In vivo & Fish & $(38)$ \\
\hline DNA methylation & $\begin{array}{l}\text { - Decrease of spermatocytes } \\
\text { - Increase in apoptosis } \\
\text { - Downregulation of CCNB1 and SYCP3 } \\
\text { - Upregulation of GPER1 and ESRRGA receptors } \\
\text { - Miss-regulation of epigenetic remodeling enzyme transcripts } \\
\text { - DNA hypermethylation } \\
\text { - H3K27me3 demethylation } \\
\text { - Increase in histone acetyltransferase activity }\end{array}$ & In vitro & Fish & (39) \\
\hline DNA methylation & $\begin{array}{l}\text { - Di-methylation of lysine } \mathrm{K} 4 \text { on histones } \mathrm{H3} \\
\text { - Impairment of motility, concentration, and mitochondrial activity in sperm }\end{array}$ & In vivo & Human & $(40)$ \\
\hline DNA methylation & Trimethylation of histone 3 ( $\mathrm{H} 3 \mathrm{~K} 27 \mathrm{me} 3, \mathrm{H} 3 \mathrm{~K} 4 \mathrm{me} 2$, or $\mathrm{H} 3 \mathrm{~K} 4 \mathrm{me} 3)$ in sperm & In vivo & Human & $(41)$ \\
\hline DNA methylation & Hypomethylation of LINE-1 & In vivo & Human & $(42)$ \\
\hline DNA methylation & $\begin{array}{l}\text { - Decrease in sperm LINE-1 methylation status } \\
\text { - Association between BPA urinary levels and low semen quality }\end{array}$ & In vivo & Human & (43) \\
\hline DNA methylation & $\begin{array}{l}\text { - Correlation between } 5 \mathrm{hmC} \text { rates of } \mathrm{AChE} \text { and low sperm motility } \\
\text { - Correlation between HoxC4 promoters and sperm concentration }\end{array}$ & In vivo & Human & (44) \\
\hline
\end{tabular}


TABLE 5 | Characteristics of the studies which analyzed the transgenerational effects of BPA exposure.

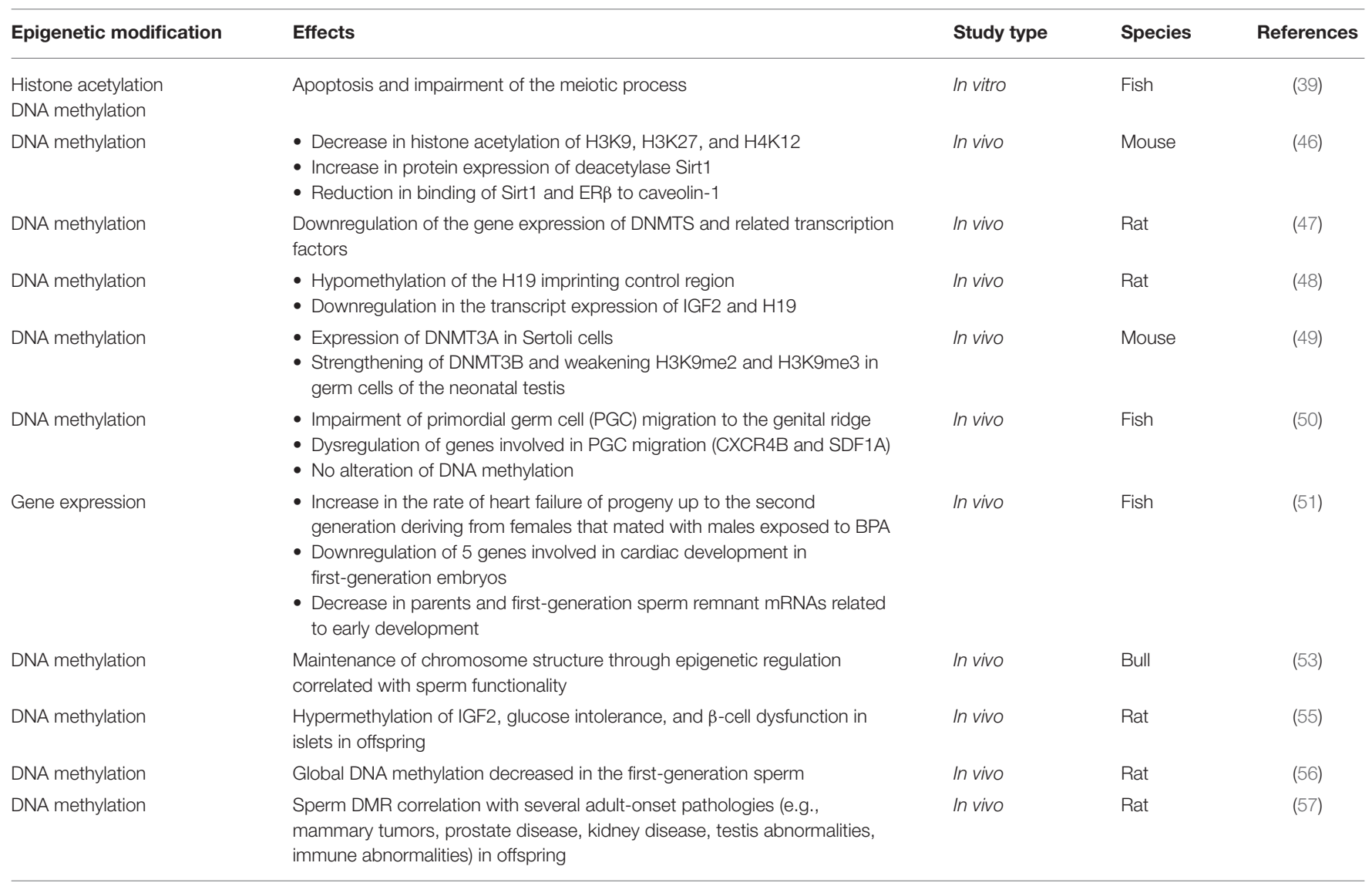

TABLE 6 | Characteristics of the studies which analyzed the risk of prostate cancer induced by BPA exposure.

\begin{tabular}{|c|c|c|c|c|}
\hline Epigenetic modification & Effects & Study type & Species & References \\
\hline DNA methylation & Hypomethylation of the prostate cancer gene (PDE4D4) & In vivo/In vitro & Human & (59) \\
\hline DNA methylation & $\begin{array}{l}\text { - Aberrant NSBP1 promoter demethylation and transcriptional } \\
\text { overexpression persisting in adult life } \\
\text { - } \text { Aberrant HPCAL1 promoter hypermethylation and transcriptional } \\
\text { suppression with a little degree of gene expression in adult life } \\
\text { - High expression of DNMT3A and DNMT3B in early life, diminishing with } \\
\text { aging } \\
\text { - Involvement in early-life reprogramming of DNA methylation patterns in } \\
\text { target genes such as NSBP1 or HPCAL1 }\end{array}$ & In vitro & Rat & (63) \\
\hline DNA methylation & $\begin{array}{l}\text { DNA methylation-mediated gene expression of } 6 \text { genes linked to embryonic } \\
\text { stem cell pluripotency }\end{array}$ & In vivo & Rat & (64) \\
\hline DNA methylation & DNA hypomethylation of genes that confer carcinogenic risk & In vivo & Rat & (65) \\
\hline DNA methylation & Deregulation of EZH2, DNMT1, DNMT3B and UHRF1 & In vitro & Human & $(66)$ \\
\hline DNA methylation & $\begin{array}{l}\text { - Expression levels of p16 gene decreased significantly after promoter } \\
\text { hypermethylation } \\
\text { - p16-related histone modifications } \\
\text { - Dose-dependent promoter hypermethylation of tumor suppressor genes } \\
\text { as BCR, PTGS2, TIMP3, and ZMYDN10 } \\
\text { - Hypomethylation of PDLIM4 and PYCARD } \\
\text { - Demethylation of GSTP1, LOX, MGMT, NEUROG, and TSC2 } \\
\text { - Significant decrease of gene expression levels and downregulation of } \\
\text { KDM5B and NSD1 measured in RT-PCR (real-time polymerase } \\
\text { chain reaction) }\end{array}$ & In vitro & Human & $(67)$ \\
\hline
\end{tabular}


of chromatin-modifying enzymes like KDM5B and NSD1 (67).

\section{DISCUSSION}

Our review intended to highlight the mechanisms by which BPA modifies at various levels the reproductive system. In particular, we looked into literature and summarized the studies that analyzed the epigenetic changes leading to impairment of the different aspects of male reproduction, both in animals and in humans.

Epigenetics is responsible for the control of many genes implicated in hormonal production, sperm parameters, and inheritable abnormalities (Tables 2-6).

The interesting point that comes out from our analysis is that BPA acts on two levels of epigenetic changes. In fact, on the one hand, it is responsible for the widely altered DNA methylation, the most commonly studied epigenetic mechanism; on the other hand, studies showed that the main effect of bisphenol $\mathrm{A}$ is on genes related to methylation proteins. In other words, BPA might be considered as an example of a proper epigenetic controller.

In this paper, we have also illustrated the possible strategies to counteract the epigenetic effect of BPA. Indeed, several antioxidants can ameliorate reproductive function by inhibiting BPA's effect on oxidative stress (68-70).

Since the increase in ROS (reactive oxygen species) is one of the recognized effects of BPA in male spermatogenesis, causing reduction in sperm viability and motility, due also to mitochondrial dysfunction, a study explored the efficacy of taurine in reversing such events, although not properly epigenetic changes, observing good results in a dose-dependent fashion (71). N-Acetylcysteine also has been evaluated to reduce ROS after BPA exposure, showing amelioration of sperm motility (36).

As abovementioned, flavonoids can defend from the epigenetic modifications induced by bisphenol A, due to their antioxidant and similar estrogenic properties (17). In addition, thanks to its antioxidant and free radical scavenger properties, melatonin has been demonstrated to pass the blood-testis barrier and protect steroidogenesis and spermatogenesis, acting principally on $\mathrm{H} 3 \mathrm{~K} 9 \mathrm{me} 2$ and DNA methylation $(20,72)$.

Folates are methyl donors, essential for the DNA methylation process and for stabilization of the methylation status of the epigenome. Mao et al. (73) studied the efficacy of folate supplementation during pregnancy in restoring pancreatic function after BPA administration in rats, obtaining a reversal of its epigenetic changes. Moreover, Dolinoy et al. (74) demonstrated that supplementation with folate or phytoestrogen as genistein during pregnancy could counteract the effects

\section{REFERENCES}

1. Mileva G, Baker SL, Konkle AT, Bielajew C. Bisphenol-A: epigenetic reprogramming and effects on reproduction and behavior. Int J Environ Res Public Health. (2014) 11:7537-61. doi: 10.3390/ijerph110707537

2. Gore AC, Chappell VA, Fenton SE, Flaws JA, Nadal A, Prins GS, et al. EDC-2: the endocrine society's second scientific statement on endocrine-disrupting of BPA exposure in Agouti mice, showing reduction in the hypomethylation pattern and hence pelage modification. These studies support that the transgenerational effects of BPA could be reduced by folate administration.

In 2011, Hardy and Tollefsbol coined the term "epigenetic diet" to refer to the dietary intake of all the compounds with protective properties against epigenetic modifications, including folates, isothiocyanates, isoflavones, resveratrol, curcumin, and tea polyphenols, among others (75). However, data on therapeutic options to reduce the impact of BPA are still quite scarce.

To the best of our knowledge, this is the first comprehensive narrative review on BPA-induced epigenetic changes and its consequence on male reproductive health. Indeed, we explored the effect of BPA in any aspect of reproductive system anomalies, considering different species. Furthermore, various epigenetic targets of $\mathrm{BPA}$ in reproductive disorders were also analyzed. On the other hand, we recognize that this led us also to a limitation, since we did not apply a systematic approach.

Given the relevant epigenetic effect of BPA and other EDCs, it could be useful in future to define specific epigenetic markers associated with male reproductive dysfunction during preconceptional analysis $(8,76,77)$. In addition, since epigenetic changes can be potentially treated, target therapies could represent a very interesting topic of study in order to preserve fertility in subsequent generations.

\section{CONCLUSION}

Exposure to BPA has the potential to induce epigenetic modifications in both animal and human cells. Such modifications could in turn play a role in male reproductive disorders and cancer development. An epigenetic transmission to offspring was also demonstrated.

Further research is needed to define the mechanisms underlying BPA-related epigenetic changes in paternal sperm and offspring phenotype and to find appropriate therapies to reduce the impact of BPA-induced dysfunctions.

\section{AUTHOR CONTRIBUTIONS}

FC, IS, and AC contributed to the conception and design of the study. AC, FB, and CC organized the database. FC and LC wrote the first draft of the manuscript. CB, IS, EA, SP, and CA wrote the sections of the manuscript. All authors contributed to the manuscript revision, read, and approved the submitted version. 
controlled ovarian stimulation in IVF/ICSI cycles: a pilot study. J Ovarian Res. (2014) 7:67. doi: 10.1186/1757-2215-7-67

5. Ma Y, Liu H, Wu J, Yuan L, Wang Y, Du X, et al. The adverse health effects of bisphenol A and related toxicity mechanisms. Environ Res. (2019) 176:108575. doi: 10.1016/j.envres.2019.108575

6. Lombó M, Fernández-Díez C, González-Rojo S, Herráez MP. Genetic and epigenetic alterations induced by bisphenol A exposure during different periods of spermatogenesis: from spermatozoa to the progeny. Sci Rep. (2019) 9:18029. doi: 10.1038/s41598-019-54368-8

7. Rubin BS. Bisphenol A: an endocrine disruptor with widespread exposure and multiple effects. J Steroid Biochem Mol Biol. (2011) 127:27-34. doi: 10.1016/j.jsbmb.2011.05.002

8. Pivonello C, Muscogiuri G, Nardone A, Garifalos F, Provvisiero DP, Verde N, et al. Bisphenol A: an emerging threat to female fertility. Reprod Biol Endocrinol. (2020) 18:22. doi: 10.1186/s12958-0190558-8

9. Cariati F, D’Uonno N, Borrillo F, Iervolino S, Galdiero G, Tomaiuolo R. Bisphenol A: an emerging threat to male fertility. Reprod Biol Endocrinol. (2019) 17:6. doi: 10.1186/s12958-018-0447-6

10. Song X, Miao M, Zhou X, Li D, Tian Y, Liang H, et al. Bisphenol A exposure and sperm ACHE Hydroxymethylation in Men. Int $J$ Environ Res Public Health. (2019) 16:E152. doi: 10.3390/ijerph160 10152

11. Chianese R, Troisi J, Richards S, Scafuro M, Fasano S, Guida $\mathrm{M}$, et al. Bisphenol A in reproduction: epigenetic effects. Curr Med Chem. (2018) 25:748-70. doi: 10.2174/0929867324666171009 121001

12. Csaba G. The crisis of the hormonal system: the health-effects of endocrine disruptors. Orv Hetil. (2017) 158:1443-51. doi: 10.1556/650.2017. 30855

13. Zhang Y, Yuan C, Gao J, Liu Y, Wang Z. Testicular transcript responses in rare minnow Gobiocypris rarus following different concentrations bisphenol A exposure. Chemosphere. (2016) 156:357-66. doi: 10.1016/j.chemosphere.2016.05.006

14. Salian S, Doshi T, Vanage G. Perinatal exposure of rats to Bisphenol A affects fertility of male offspring-an overview. Reprod Toxicol. 2011 31:35962. doi: 10.1016/j.reprotox.2010.10.008

15. Doshi T, Mehta SS, Dighe V, Balasinor N, Vanage G. Hypermethylation of estrogen receptor promoter region in adult testis of rats exposed neonatally to bisphenol A. Toxicology. (2011) 289:74-82. doi: 10.1016/j.tox.2011. 07.011

16. El Henafy HMA, Ibrahim MA, Abd El Aziz SA, Gouda EM. Oxidative stress DNA methylation in male rat pups provoked by the transplacental translactational exposure to bisphenol A. Environ Sci Pollut Res Int. (2020) 27:4513-9. doi: 10.1007/s11356-019-06553-5

17. Wei Y, Han C, Li S, Cui Y, Bao Y, Shi W. Cuscuta chinensis flavonoids down-regulate the DNA methylation of the H19/Igf2 imprinted control region and estrogen receptor alpha promoter of the testis in bisphenol $\mathrm{A}$ exposed mouse offspring. Food Funct. (2020) 11:787-98. doi: 10.1039/C9FO 02770J

18. Kataria A, Levine D, Wertenteil S, Vento S, Xue J, Rajendiran K, et al. Exposure to bisphenols and phthalates and association with oxidant stress, insulin resistance, and endothelial dysfunction in children. Pediatr Res. (2017) 81:857-64. doi: 10.1038/pr.2017.16

19. Menezo YJ, Silvestris E, Dale B, Elder K. Oxidative stress and alterations in DNA methylation: two sides of the same coin in reproduction. Reprod Biomed Online. (2016) 33:668-83. doi: 10.1016/j.rbmo.2016.09.006

20. Zhang T, Zhou Y, Li L, Zhao Y, De Felici M, Reiter RJ, et al. Melatonin protects prepuberal testis from deleterious effects of bisphenol A or diethylhexyl phthalate by preserving H3K9 methylation. J Pineal Res. (2018) 65:e12497. doi: 10.1111/jpi.12497

21. Hong J, Chen F, Wang X, Bai Y, Zhou R, Li Y, et al. Exposure of preimplantation embryos to low-dose bisphenol A impairs testes development and suppresses histone acetylation of StAR promoter to reduce production of testosterone in mice. Mol Cell Endocrinol. (2016) 427:10111. doi: 10.1016/j.mce.2016.03.009

22. Moreman J, Lee O, Trznadel M, David A, Kudoh T, Tyler CR. Acute toxicity, teratogenic, and estrogenic effects of bisphenol $\mathrm{A}$ and its alternative replacements bisphenol S. bisphenol F, and bisphenol AF in zebrafish embryo-larvae. Environ Sci Technol. (2017) 51:12796805. doi: 10.1021 /acs.est.7b03283

23. Sadler-Riggleman I, Klukovich R, Nilsson E, Beck D, Xie Y, Yan W, et al. Epigenetic transgenerational inheritance of testis pathology and sertoli cell epimutations: generational origins of male infertility. Environ Epigenet. (2019) 5:dvz013. doi: 10.1093/eep/dvz013

24. Cho H, Kim SJ, Park H, Oh M-J, Yu SY, Park C, et al. A relationship between miRNA and gene expression in the mouse sertoli cell line after exposure to bisphenol A. BioChip J. (2010) 4:75-81. doi: 10.1007/s13206-01 0-4112-1

25. Pawlicki P, Duliban M, Tuz R, Ptak A, Milon A, Gorowska-Wojtowicz E, et al. Do G-protein coupled estrogen receptor and bisphenol A analogs influence on Leydig cell epigenetic regulation in immature boar testis ex vivo? Anim Reprod Sci. (2019) 207:21-35. doi: 10.1016/j.anireprosci.2019. 06.006

26. Oakes CC, La Salle S, Smiraglia DJ, Robaire B, Trasler JM. A unique configuration of genome-wide DNA methylation pattern in the testis. Proc Nat Acad Sci USA. (2007) 104:228-33. doi: 10.1073/pnas.06075 21104

27. Stuppia L, Franzago M, Ballerini P, Gatta V, Antonucci I. Epigenetics and male reproduction: the consequences of paternal lifestyle on fertility, embryo development, and children lifetime health. Clin Epigenetics. (2015) 7:120. doi: 10.1186/s13148-015-0155-4

28. Luense LJ, Donahue G, Lin-Shiao E, Rangel R, Weller AH, Bartolomei MS, et al. Gcn5-Mediated histone acetylation governs nucleosome dynamics in spermiogenesis. Dev Cell. (2019) 51:745-58.e6. doi: 10.1016/j.devcel.2019.10.024

29. Miller D, Brinkworth M, Iles D. Paternal DNA packaging in spermatozoa: more than the sum of its parts? DNA histones, protamines and epigenetics. Reproduction. (2010) 139:287- 301. doi: 10.1530/REP09-0281

30. Li Y, Duan F, Zhou X, Pan H, Li R. Differential responses of GC-1 spermatogonia cells to high and low doses of bisphenol A. Mol Med Rep. (2018) 18:3034-40. doi: 10.3892/mmr.2018.9256

31. Zhang GL, Zhang XF, Feng YM, Li L, Huynh E, Sun XF, et al. Exposure to bisphenol A results in a decline in mouse spermatogenesis. Reprod Fertil Dev. (2013) 25:847-59. doi: 10.1071/RD12159

32. Yin L, Dai Y, Jiang X, Liu Y, Chen H, Han F, et al. Role of DNA methylation in bisphenol A exposed mouse spermatocyte. Environ Toxicol Pharmacol. (2016) 48:265-71. doi: 10.1016/j.etap.2016.11.003

33. Yuan C, Zhang Y, Liu Y, Zhang T, Wang Z. Enhanced GSH synthesis by bisphenol A exposure promoted DNA methylation process in the testes of adult rare minnow Gobiocypris rarus. Aquat Toxicol. (2016) 178:99105. doi: 10.1016/j.aquatox.2016.07.015

34. Liu Y, Yuan C, Chen S, Zheng Y, Zhang Y, Gao J, et al. Global and cyp19ala gene specific DNA methylation in gonads of adult rare minnow Gobiocypris rarus under bisphenol A exposure. Aquat Toxicol. (2014) 156:106. doi: 10.1016/j.aquatox.2014.07.017

35. Laing LV, Viana J, Dempster EL, Trznadel M, Trunkfield LA, Uren Webster TM, et al. Bisphenol A causes reproductive toxicity, decreases dnmtl transcription, and reduces global DNA methylation in breeding zebrafish (Danio rerio). Epigenetics. (2016) 11:526-38. doi: 10.1080/15592294.2016.1182272

36. Yuan C, Wang L, Zhu L, Ran B, Xue X, Wang Z. N-acetylcysteine alleviated bisphenol A-induced testicular DNA hypermethylation of rare minnow (Gobiocypris rarus) by increasing cysteine contents. Ecotoxicol Environ Saf. (2019) 173:243-50. doi: 10.1016/j.ecoenv.2019.02.035

37. Yuan C, Zhang Y, Liu Y, Wang S, Wang Z. DNA demethylation mediated by down-regulated TETs in the testes of rare minnow Gobiocypris rarus under bisphenol A exposure. Chemosphere. (2017) 171:355-61. doi: 10.1016/j.chemosphere.2016.12.098

38. Liu Y, Zhang Y, Tao S, Guan Y, Zhang T, Wang Z. Global DNA methylation in gonads of adult zebrafish Danio rerio under bisphenol A exposure. Ecotoxicol Environ Saf. (2016) 130:124-32. doi: 10.1016/j.ecoenv.2016. 04.012

39. González-Rojo S, Lombó M, Fernández-Díez C, Herráez MP. Male exposure to bisphenol a impairs spermatogenesis and triggers histone 
hyperacetylation in zebrafish testes. Environ Pollut. (2019) 248:36879. doi: 10.1016/j.envpol.2019.01.127

40. tiavnická M, García-Álvarez O, Ulčová-Gallová Z, Sutovsky P, Abril-Parreño L, Dolejšová M. H3K4me2 accompanies chromatin immaturity in human spermatozoa: an epigenetic marker for sperm quality assessment. Syst Biol Reprod Med. (2020) 66:3-11. doi: 10.1080/19396368.2019.1666435

41. Zheng H, Zhou X, Li DK, Yang F, Pan H, Li T, et al. Genome-wide alteration in DNA hydroxymethylation in the sperm from bisphenol A-exposed men. PLoS ONE. (2017) 12:e0178535. doi: 10.1371/journal.pone.0178535

42. Tian Y, Zhou X, Miao M, Li DK, Wang Z, Li R, et al. Association of bisphenol a exposure with line-1 hydroxymethylation in human semen. Int J Environ Res Public Health. (2018) 15:1770. doi: 10.3390/ijerph15081770

43. Miao M, Zhou X, Li Y, Zhang O, Zhou Z, Li T, et al. LINE-1 hypomethylation in spermatozoa is associated with bisphenol A exposure. Andrology. (2014) 2:138-44. doi: 10.1111/j.2047-2927.2013.00166.x

44. Li Y, Li YH, Zhou X, Wu B, Chen JP, Wang ZK, et al. DNA hydroxymethylation rate in the $\mathrm{AChE}$ and $\mathrm{HoxC} 4$ promoter associated with human sperm quality. Andrologia. (2018) 50:e12963. doi: 10.1111/and.12963

45. Kalish JM, Jiang C, Bartolomei MS. Epigenetics and imprinting in human disease. Int J Dev Biol. (2014) 58:291-8. doi: 10.1387/ijdb.140077mb

46. Chen Z, Zuo X, He D, Ding S, Xu F, Yang H, et al. Long-term exposure to a 'safe' dose of bisphenol A reduced protein acetylation in adult rat testes. Sci Rep. (2017) 7:40337. doi: 10.1038/srep40337

47. Doshi T, D'Souza C, Dighe V, Vanage G. Effect of neonatal exposure on male rats to bisphenol A on the expression of DNA methylation machinery in the postimplantation embryo. J Biochem Mol Toxicol. (2012) 26:33743. doi: $10.1002 / j b t .21425$

48. Doshi T, D'souza C, Vanage G. Aberrant DNA methylation at Igf2-H19 imprinting control region in spermatozoa upon neonatal exposure to bisphenol A and its association with post implantation loss. Mol Biol Rep. (2013) 40:4747-57. doi: 10.1007/s11033-013-2571-x

49. Shi M, Whorton AE, Sekulovski N, MacLean JA, Hayashi K. Prenatal exposure to bisphenol $\mathrm{A}, \mathrm{E}$, and $\mathrm{S}$ induces transgenerational effects on male reproductive functions in mice. Toxicol Sci. (2019) 172:30315. doi: 10.1093/toxsci/kfz207

50. Lombó M, Getino-Álvarez L, Depincé A, Labbé C, Herráez MP. Embryonic exposure to bisphenol a impairs primordial germ cell migration without jeopardizing male breeding capacity. Biomolecules. (2019) 9:307. doi: 10.3390/biom9080307

51. Lombó M, Fernández-Díez C, González-Rojo S, Navarro C, Robles V, Herráez MP. Transgenerational inheritance of heart disorders caused by paternal bisphenol A exposure. Environ Pollut. (2015) 206:66778. doi: 10.1016/j.envpol.2015.08.016

52. Akhter A, Rahaman M, Suzuki RT, Murono Y, Tokumoto T. Next-generation and further transgenerational effects of bisphenol A on zebrafish reproductive tissues. Heliyon. (2018) 4:e00788. doi: 10.1016/j.heliyon.2018.e00788

53. Capra E, Lazzari B, Turri F, Cremonesi P, Portela AMR, AjmoneMarsan P, et al. Epigenetic analysis of high and low motile sperm populations reveals methylation variation in satellite regions within the pericentromeric position and in genes functionally related to sperm DNA organization and maintenance in Bos taurus. BMC Genomics. (2019) 20:940. doi: 10.1186/s12864-019-6317-6

54. Burlibaşa L, Ionescu AC, Dragusanu DM. Histone hyperacetylation and DNA methylation interplay during murine spermatogenesis. Zygote. (2019) 27:305-14. doi: $10.1017 /$ S0967199419000303

55. Mao Z, Xia W, Chang H, Huo W, Li Y, Xu S. Paternal BPA exposure in early life alters Igf2 epigenetic status in sperm and induces pancreatic impairment in rat offspring. Toxicol Lett. (2015) 238:30-8. doi: 10.1016/j.toxlet.2015.08.009

56. Li G, Chang H, Xia W, Mao Z, Li Y, Xu S. F0 maternal BPA exposure induced glucose intolerance of F2 generation through DNA methylation change in Gck. Toxicol Lett. (2014) 228:192-9. doi: 10.1016/j.toxlet.2014.04.012

57. Manikkam M, Guerrero-Bosagna C, Tracey R, Haque MM, Skinner MK. Transgenerational actions of environmental compounds on reproductive disease and identification of epigenetic biomarkers of ancestral exposures. PLoS ONE. (2012) 7:e31901. doi: 10.1371/journal.pone.0031901

58. Manikkam M, Tracey R, Guerrero-Bosagna C, Skinner MK. Plastics derived endocrine disruptors (BPA, DEHP and DBP) induce epigenetic transgenerational inheritance of obesity, reproductive disease and sperm epimutations. PLoS ONE. (2013) 8:e55387. doi: 10.1371/journal.pone.0055387

59. Ho SM, Tang WY, Belmonte de Frausto J, Prins GS. Developmental exposure to estradiol and bisphenol A increases susceptibility to prostate carcinogenesis and epigenetically regulates phosphodiesterase type 4 variant 4. Cancer Res. (2006) 66:5624-32. doi: 10.1158/0008-5472.CAN06-0516

60. Prins GS, Birch L, Tang WY, Ho SM. Developmental estrogen exposures predispose to prostate carcinogenesis with aging. Reprod Toxicol. (2007) 23:374-82. doi: 10.1016/j.reprotox.2006. 10.001

61. Prins GS, Tang WY, Belmonte J, Ho SM. Perinatal exposure to oestradiol and bisphenol A alters the prostate epigenome and increases susceptibility to carcinogenesis. Basic Clin Pharmacol Toxicol. (2008) 102:134-8. doi: 10.1111/j.1742-7843.2007.00166.x

62. Prins GS, Tang WY, Belmonte J, Ho SM. Developmental exposure to bisphenol A increases prostate cancer susceptibility in adult rats: epigenetic mode of action is implicated. Fertil Steril. (2008) 89(Suppl. 2):e41. doi: 10.1016/j.fertnstert.2007.12.023

63. Tang WY, Morey LM, Cheung YY, Birch L, Prins GS, Ho SM. Neonatal exposure to estradiol/bisphenol A alters promoter methylation and expression of Nsbp1 and Hpcall genes and transcriptional programs of Dnmt3a/b and $\mathrm{Mbd} 2 / 4$ in the rat prostate gland throughout life. Endocrinology. (2012) 153:42-55. doi: 10.1210/en.2011-1308

64. Cheong A, Zhang X, Cheung YY, Tang WY, Chen J, Ye SH, et al. DNA methylome changes by estradiol benzoate and bisphenol A links early-life environmental exposures to prostate cancer risk. Epigenetics. (2016) 11:67489. doi: 10.1080/15592294.2016.1208891

65. Prins GS, Ye SH, Birch L, Zhang X, Cheong A, Lin H, et al. Prostate cancer risk and DNA methylation signatures in aging rats following developmental BPA exposure: a dose-response analysis. Environ Health Perspect. (2017) 125:077007. doi: 10.1289/EHP1050

66. Renaud L, Huff $M$, da Silveira WA, Angert $M$, Haas $M$, Hardiman G. Genome-wide analysis of low dose bisphenol-A (BPA) exposure in human prostate cells. Curr Genomics. (2019). 20:260-74. doi: 10.2174/1389202920666190603123040

67. Fatma Karaman E, Caglayan M, Sancar-Bas S, Ozal-Coskun C, ArdaPirincci P, Ozden S. Global and region-specific post-transcriptional and post-translational modifications of bisphenol $\mathrm{A}$ in human prostate cancer cells. Environ pollut. (2019) 255:113318. doi: 10.1016/j.envpol.2019. 113318

68. Grami D, Rtibi K, Selmi S, Jridi M, Sebai H, Marzouki L, et al. Aqueous extract of Eruca Sativa protects human spermatozoa from mitochondrial failure due to bisphenol A exposure. Reprod Toxicol. (2018) 82:10310. doi: 10.1016/j.reprotox.2018.10.008

69. Grami D, Rtibi K, Hammami I, Selmi S, De Toni L, Foresta C, et al. Protective action of eruca sativa leaves aqueous extracts against bisphenol a-caused in vivo testicular damages. J Med Food. (2019) 23:60010. doi: 10.1089/jmf.2019.0170

70. Alviggi C, Cariati F, Conforti A, De Rosa P, Vallone R, Strina I, et al. The effect of FT500 Plus $\left({ }^{\circledR}\right)$ on ovarian stimulation in PCOS women. Reprod Toxicol. (2016) 59:40-4. doi: 10.1016/j.reprotox.2015. 10.014

71. Rezaee-Tazangi F, Zeidooni L, Rafiee Z, Fakhredini F, Kalantari H, Alidadi $\mathrm{H}$, et al. Taurine effects on bisphenol A-induced oxidative stress in the mouse testicular mitochondria and sperm motility. JBRA Assist Reprod. (2020) doi: 10.5935/1518-0557.20200017. [Epub ahead of print].

72. Wu HJ, Liu C, Duan WX, Xu SC, He MD, Chen CH, et al. Melatonin ameliorates bisphenol A-induced DNA damage in the germ cells of adult male rats. Mutat. Res. (2013) 752:57-67. doi: 10.1016/j.mrgentox.2013. 01.005

73. Mao Z, Xia W, Huo W, Zheng T, Bassig BA, Chang H, et al. Pancreatic impairment and Igf2 hypermethylation induced by developmental exposure to bisphenol A can be counteracted by maternal folate supplementation. J. Appl. Toxicol. (2017) 37:825-35. doi: 10.1002/jat.3430

74. Dolinoy DC, Huang D, Jirtle RL. Maternal nutrient supplementation counteracts bisphenol A-induced DNA hypomethylation in 
early development. Proc Natl Acad Sci USA. (2007) 104:1305661. doi: $10.1073 /$ pnas. 0703739104

75. Hardy TM, Tollefsbol TO. Epigenetic diet: impact on the epigenome and cancer. Epigenomics. (2011) 3:503-18. doi: 10.2217/epi.11.71

76. Cariati F, D'Argenio V, Tomaiuolo R. The evolving role of genetic tests in reproductive medicine. J Transl Med. (2019). 17:267. doi: 10.1186/s12967-019-2019-8

77. Cariati F, Jaroudi S, Alfarawati S, Raberi A, Alviggi C, Pivonello R, et al. Investigation of sperm telomere length as a potential marker of paternal genome integrity and semen quality. Reprod Biomed. (2016) 33:40411. doi: 10.1016/j.rbmo.2016.06.006
Conflict of Interest: The authors declare that the research was conducted in the absence of any commercial or financial relationships that could be construed as a potential conflict of interest.

Copyright (c) 2020 Cariati, Carbone, Conforti, Bagnulo, Peluso, Carotenuto, Buonfantino, Alviggi, Alviggi and Strina. This is an open-access article distributed under the terms of the Creative Commons Attribution License (CC BY). The use, distribution or reproduction in other forums is permitted, provided the original author(s) and the copyright owner(s) are credited and that the original publication in this journal is cited, in accordance with accepted academic practice. No use, distribution or reproduction is permitted which does not comply with these terms. 